Article

\title{
Evaluation of the Durability and the Property of an Asphalt Concrete with Nano Hydrophobic Silane Silica in Spring-Thawing Season
}

\author{
Wei Guo ${ }^{1}$, Xuedong Guo ${ }^{1}$, Mingzhi Sun ${ }^{2}$ and Wenting Dai ${ }^{1, *(D)}$ \\ 1 School of Transportation, Jilin University, Changchun 130022, China; guowei17@mails.jlu.edu.cn (W.G.); \\ guoxd@jlu.edu.cn (X.G.) \\ 2 Research Institute of Highway, Ministry of Transport of China, Beijing 100088, China; \\ mzsun14@mails.jlu.edu.cn \\ * Correspondence: daiwtl@jlu.edu.cn; Tel.: +86-130-8681-4298
}

Received: 12 July 2018; Accepted: 24 August 2018; Published: 28 August 2018

Featured Application: This paper proved that adding Nano Hydrophobic Silane Silica is an effective technique for mitigating freeze-thaw cycle damage of asphalt concrete in spring-thawing season. Moreover, it's found that the freeze factor had a more significant impact on the damage process of asphalt concrete compared with the soak and scour factor, which provides suggestions for pavement construction in seasonal frozen region.

\begin{abstract}
In the spring-thawing season, the high frequency of freeze-soak-scour cycles in the short term is the main cause of pavement damage in the frozen region. One of the methods to improve the durability of asphalt concrete in spring-thawing season is to add suitable modifiers and additives which improve adhesion between asphalt binder and aggregate. This study evaluates the effect of nano hydrophobic silane silica (NHSS) on the performance damage of asphalt concrete (AC) in spring-thawing season. The effectiveness of nano hydrophobic silane silica was evaluated by conducting mixture tests after different freeze-soak-scour cycles, and the damage model of NHSS modified asphalt concrete was established based on the logistic damage model. The results showed that adding NHSS is an effective technique for mitigating freeze-soak-scour cycle damage of asphalt concrete in spring-thawing season. Moreover, the influence of scour, soak, and freeze-three separate factors on NHSS-modified AC in spring-thawing season-was discussed based the gray rational degree theory. The results illustrated that the freeze factor had a more significant impact on the damage process of NHSS modified asphalt concrete compared with the soak and scour factor.
\end{abstract}

Keywords: nano hydrophobic silane silica; spring-thawing season; damage evolution; damage model; gray rational degree theory

\section{Introduction}

The seasonal frozen region covers a large area in China, accounting for $53.5 \%$ of the country's land area. The high frequency of freeze-thaw cycles in the short term is the main cause of pavement damage in the season frozen region. This damage leads to an increase of maintenance cost and decrease in the service life of pavement [1,2]. Despite the developments that have increased the understanding of asphalt mixture behavior and mix design, freeze-thaw cycle damage is still considered a complex problem in asphalt pavements [3-5].

In recent years, the evolution of asphalt mixtures under freeze-thaw cycles was evaluated by various research [6-10] used the logistic model to study the effects of freeze-thaw cycles on the 
compressibility of mixture [11]. Gong et al. studied the effects of freeze-thaw cycles on the low temperature performance of mixture [12]. Islam et al. studied the effects of freeze-thaw cycles on the strength of mixture [13]. In conclusion, the freeze-thaw cycle damage in asphalt mixtures can be defined as the loss of strength and stiffness of mix because moisture migration and accumulation under the high frequency of freeze-thaw cycles. In the spring-thawing season, free water formed by the melting of snow on the pavement penetrates into the interior of the pavement structure due to the rising daytime temperature. The volume of free water expands after being frozen, which generates internal temperature stress in the mixture, and this effect can enlarge the micropores and original cracks in the asphalt layer. The ice crystalloids are transformed into free water which cause moisture damage with the increase of temperature. Moreover, the free water forms' scouring, squeezing, and pumping effects on the internal structure of pavement under the traffic load cause asphalt pavement distress - such as strength losing, rutting, raveling, and fatigue cracking [14].

Because of the complexity of the freeze-thaw cycle damage phenomenon, using proper additives and modifiers is considered the most cost-effective technique for mitigating freeze-thaw cycle damage. Wei et al. investigated the effect of diatomite and styrene butadiene styrene on antifreezing performance of crumb rubber modified stone mastic asphalt (SMA), the results indicate that crumb rubber and diatomite modified SMA has the good freeze-thaw resistance [15]. Klinsky et al. held that the use of polypropylene and aramid fibers in HMA could enhance the performance of asphalt pavements against common distresses [16]. Zhang et al. found that micro or nano zinc oxide can significantly improve the anti-freeze-thaw performance of asphalt and asphalt mixture [17]. Qian et al. found that phosphorus slag powder modified by TM-P ( $10 \%$ by weight of the powder) improved freeze-thaw resistance of asphalt mixture [18]. Hamedi evaluated the effects of two types of nanomaterials in two different percentages (nano $\mathrm{Al}_{2} \mathrm{O}_{3}$ and $\mathrm{Fe}_{2} \mathrm{O}_{3}$ ), two types of aggregates (granite and quartzite), and one base asphalt binder. The results showed that asphalt binder modification with nanomaterials decreases the moisture damage susceptibility [19].

Among the existing modifiers, natural and synthetic polymers are widely used to improve the durability and the properties of asphalt concrete in spring-thawing season, but such a modifier presents a serious isolation problem that restricts its application in modifying paving asphalt. Nano hydrophobic silane silica (NHSS) draws much attention at present because of its high compatibility, and its capability to improve base asphalt properties. The nano hydrophobic silane silica (NHSS) is obtained by the surface modification of nanosilica by silane coupling agent, which can greatly improve the dispersibility of modified nanosilica in the organic polymer, so that the whole system has better stability, and the advantages of nanosilica and silane coupling agent can be fully utilized in the mixed system. To the authors' knowledge, the open literature has no experimental studies of nano hydrophobic silane silica modified asphalt concrete subjected to long freeze-soak-scour cycles. In this study, a laboratory freeze-soak-scour cycle test was proposed to simulate the actual condition of asphalt pavement during spring-thawing season. The normal asphalt concrete and NHSS modified asphalt concrete specimens were prepared for the freeze-soak-scour cycle. After different freeze-soak-scour cycles, damaged specimens were collected for mechanical tests and internal structure parameters tests to identify the effectiveness of nano hydrophobic silane silica. Moreover, the damage model of NHSS modified asphalt concrete was established based on the logistic damage model. The influence of freeze, soak, and scour damage factors on the damage process of NHSS modified asphalt concrete in spring-thawing season is analyzed based on the gray rational degree theory.

\section{Materials}

\subsection{Aggregates}

In this study, crushed and sharp-edged aggregates (Jiutai, China, 2018) were used for preparation of AC. Physical properties of the aggregates and the gradation of AC are listed in Table 1. 
Table 1. Properties of aggregate and gradation of AC-16.

\begin{tabular}{ccccccccccc}
\hline Sieve $(\mathbf{m m})$ & $\mathbf{1 6}$ & $\mathbf{1 3 . 2}$ & $\mathbf{9 . 5}$ & $\mathbf{4 . 7 5}$ & $\mathbf{2 . 3 6}$ & $\mathbf{1 . 1 8}$ & $\mathbf{0 . 6}$ & $\mathbf{0 . 3}$ & $\mathbf{0 . 1 5}$ & $\mathbf{0 . 0 7 5}$ \\
\hline Apparent density & 2.78 & 2.78 & 2.78 & 2.74 & 2.74 & 2.75 & 2.70 & 2.70 & 2.69 & 2.67 \\
Bulk density & 2.77 & 2.76 & 2.75 & 2.68 & 2.64 & 2.59 & 2.60 & 2.59 & 2.57 & 2.55 \\
Gradation $(\%)$ & 95 & 88 & 73 & 46 & 31 & 21.5 & 15.5 & 11.5 & 5.5 & 6 \\
\hline
\end{tabular}

\subsection{Asphalt}

The asphalt (Panjin, China, 2018) was used in this study. Laboratory tests were carried out in order to assess the conventional properties of asphalt. The test results of the asphalt used in this study are summarized in Table 2.

Table 2. Technical parameters of asphalt.

\begin{tabular}{|c|c|c|c|c|c|c|c|c|c|}
\hline \multirow{2}{*}{$\begin{array}{l}\text { Technical } \\
\text { Parameters }\end{array}$} & \multicolumn{3}{|c|}{ Penetration } & \multirow{2}{*}{$\begin{array}{c}25^{\circ} \mathrm{C} \\
\text { Ductility }\end{array}$} & \multirow{2}{*}{$\begin{array}{l}\text { Softening } \\
\text { Point }\end{array}$} & \multirow{2}{*}{$\begin{array}{c}\text { Wax } \\
\text { Content }\end{array}$} & \multirow{2}{*}{$\begin{array}{l}\text { Flash } \\
\text { Point }\end{array}$} & \multirow{2}{*}{ Solubility } & \multirow{2}{*}{ Density } \\
\hline & $15^{\circ} \mathrm{C}$ & $25^{\circ} \mathrm{C}$ & $30^{\circ} \mathrm{C}$ & & & & & & \\
\hline Units & & $0.1 \mathrm{~mm}$ & & $\mathrm{~cm}$ & ${ }^{\circ} \mathrm{C}$ & $\% \leq$ & ${ }^{\circ} \mathrm{C}$ & $\% \geq$ & $\mathrm{g} \cdot \mathrm{cm}^{-3}$ \\
\hline Test results & 27.5 & 81.3 & 132.6 & $>130$ & 44.2 & 18 & 340 & 99.9 & 1.003 \\
\hline
\end{tabular}

\subsection{Nano Hydrophobic Silane Silica}

Nanosilica is recognized as a modifer of asphalt for its superior stability, thixotropy, reinforcing, and thickening properties [20-22]. Yao et al. found that the antiaging property and rutting and fatigue cracking performance of nanosilica modified asphalt binders are enhanced, and the addition of nanosilica in the control asphalt asphalt mixture significantly improves the dynamic modulus, flow number, and rutting resistance of asphalt mixtures [23]. However, the presence of a large amount of hydroxyl groups on the surface of nanosilica particles causes the nanosilica to exhibit hydrophilicity, and the hydroxyl group of nanosilica has a high surface energy due to its strong polarity. Thus, the nanosilica particles are in a thermodynamic unstable state and are easily attracted to each other to form agglomerates, which makes it difficult to mix well in asphalt and asphalt mixture, leading to poor dispersion and compatibility with asphalt binder.

In order to improve the compatibility of nanosilica in asphalt, the silane coupling agent was grafted onto the surface of nanosilica by chemical coupling to achieve surface modification of nanosilica. The surface modification method of nanosilica is detailed as follows: the $X$ group in the silane coupling agent first undergoes hydrolysis by contacting with water, and then forms a temporary oligomer by dehydration condensation. The hydroxyl groups on the surface of nanosilica can react with the oligomeric structure to generate hydrogen bonds, then the nanosilica and the oligomer continue to undergo condensation and dehydration reaction by heating, drying, etc., and finally the silane coupling agent is successfully grafted onto the surface of the nanosilica by a covalent bond, as is shown in Figure 1.

The nano hydrophobic silane silica (NHSS) is obtained by the surface modification of nanosilica by silane coupling agent, which can greatly improve the dispersibility of modified nanosilica in the organic polymer, so that the whole system has better stability, and the advantages of nanosilica and silane coupling agent can be fully utilized in the mixed system. NHSS was selected from Changtai Micro-Nano Chemical Co.,Ltd (Shouguang, Shandong, China) to be used in this study. The technical parameters of NHSS used in this study are summarized in Table 3. 
Table 3. Technical parameters of nano hydrophobic silane silica (NHSS).

\begin{tabular}{cccccccc}
\hline $\begin{array}{c}\text { Technical } \\
\text { Parameters }\end{array}$ & $\begin{array}{c}\text { BET } \\
\left(\mathbf{m}^{\mathbf{2}} / \mathbf{g}\right)\end{array}$ & $\begin{array}{c}\text { Average } \\
\text { Particle } \\
\text { Size }(\mathbf{n m})\end{array}$ & $\begin{array}{c}\text { Loss on Drying } \\
\left(\mathbf{1 0 5}{ }^{\circ} \mathbf{C}, \mathbf{2} \mathbf{h},\right. \\
\mathbf{w t} \mathbf{\%})\end{array}$ & $\begin{array}{c}\text { Loss on Ignition } \\
\left(\mathbf{1 0 0 0}{ }^{\circ} \mathbf{C}, \mathbf{2} \mathbf{~ h},\right. \\
\mathbf{w t} \mathbf{\%})\end{array}$ & $\begin{array}{c}\mathbf{p H} \\
\text { Value }\end{array}$ & $\begin{array}{c}\text { Carbon } \\
\text { Content } \\
\mathbf{( \% )}\end{array}$ & $\begin{array}{c}\mathrm{SiO}_{\mathbf{2}} \\
\text { Content } \\
\mathbf{( \% )}\end{array}$ \\
\hline Test results & $125 \pm 20$ & 12 & $\leq 0.5$ & $1.5-2.5$ & $5.0-8.0$ & $2.0-3.5$ & $\geq 99.8$ \\
\hline
\end{tabular}

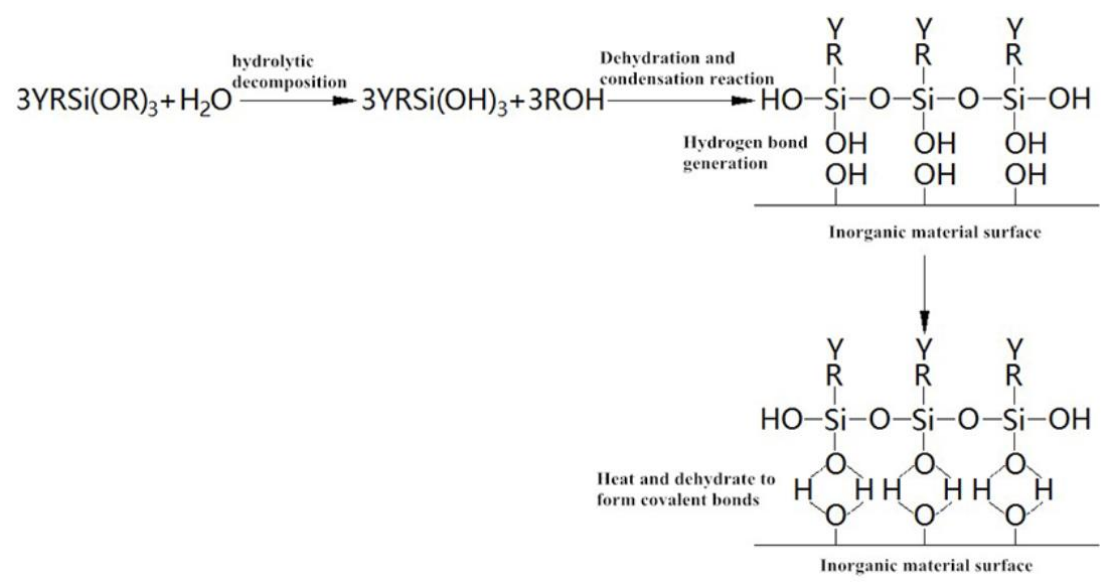

Figure 1. Grafting process of silane coupling agent on nanosilica.

The microstructure of NHSS and nanosilica were examined by SU8000 electronic microscopy (Tianmei.co, Tokyo, Japan, 2008). The scanning electron micrographs of nanosilica and NHSS observed at magnifying power of $\times 10,000$ are shown in Figure 2. (a and b). The SEM images of the matrix asphalt with 3\% nanosilica (NS-MA) and the matrix asphalt with 3\% NHSS (NHSS-MA) are demonstrated in Figure $3 \mathrm{a}, \mathrm{b}$ and the light particles observed in Figure 3 are NHSS and nanosilica.

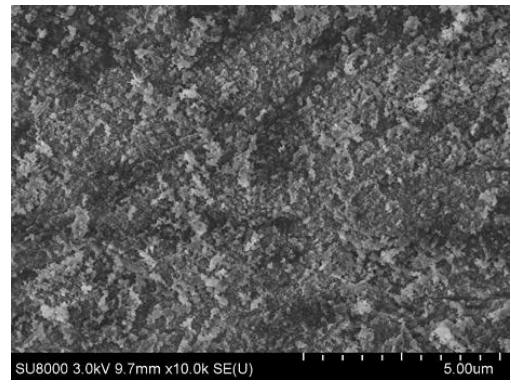

(a) Nanosilica

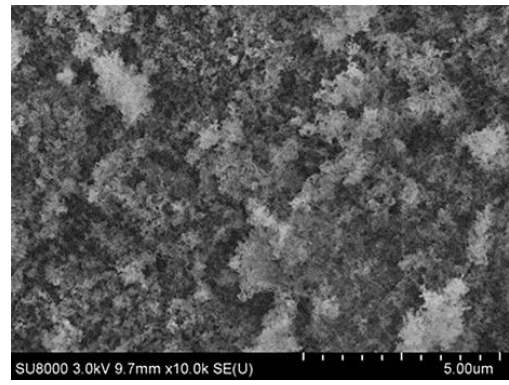

(b) NHSS

Figure 2. SEM images of nanosilica and nano hydrophobic silane silica (NHSS) at magnifications of $\times 10000$.

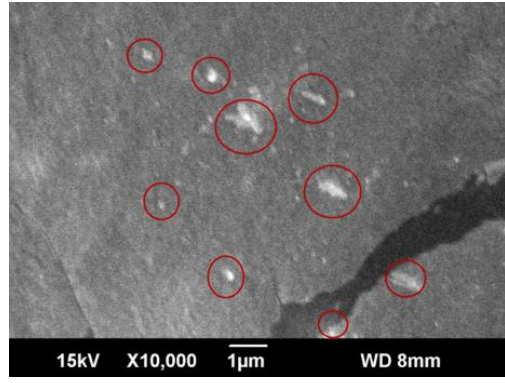

(a) NS-MA

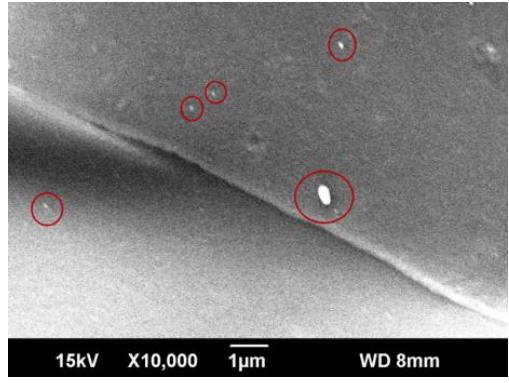

(b) NHSS-MA

Figure 3. Scanning electron micrographs of nanosilica modified asphalt and NHSS modified asphalt. 
It can be seen from Figure 2 that the surface of aggregates formed by the NHSS particles is rough compared with nanosilica particles, and the NHSS particles combine to form microchains and micro-mesh structures in three-dimensional reticular distribution. The three-dimensional distribution of NHSS particles is due to the formation of an organic film on the NHSS particles by the silane coupling agent, and the organic film reduces the tension on the surface of the particles, exerts a good steric hindrance effect, and effectively inhibits the agglomeration between the particles. Moreover, the mutilayer structure and micro-pores of NHSS particles aggregate contributed greatly to the adhesive property of modified asphalt.

From Figure 3, it can be observed that the size of NHSS particles aggregates is smaller than that of nanosilica particles aggregates in the same random region, which indicates that NHSS has better dispersibility in asphalt. The main reason for the difference of dispersion between nanosilica and NHSS in asphalt is the surface of NHSS contains a large number of atoms, which makes it easier to form a short-range annular diffusion channel in asphalt compared with the nanosilica. Thus, the NHSS has higher diffusivity in the preparation process of the modified asphalt.

\subsection{NHSS-AC Samples Preparation}

Nano hydrophobic silane silica modified asphalt samples with NHSS (1, 3, 5\% by mass of base asphalt) were prepared to determine the optimal NHSS content. Due to the high specific surface of NHSS, pre-mixing of the heated NHSS and asphalt binder is necessary for easier mixing. Firstly, base asphalt and prepared NHSS was heated to $165^{\circ} \mathrm{C}$ in an oven (2008, Xinxing Test Instruments Co. Ltd, Changchun, China) and preserved for $1 \mathrm{~h}$. After pre-mixing, a high-speed mixer (2008, Xinxing Test Instruments Co. Ltd., Changchun, China) was adopted to make the NHSS mixed more uniformly with base asphalt by maintaining a low speed of $1000 \mathrm{r} / \mathrm{min}$ for $5 \mathrm{~min}$ and proceeding to a higher speed of $3000 \mathrm{r} / \mathrm{min}$ for $15 \mathrm{~min}$ afterwards. The property tests of NHSS modified asphalt samples were conducted to determine the optimal NHSS content. The results are shown in Table 4.

Table 4. Property parameters of modified asphalt with different NHSS.

\begin{tabular}{|c|c|c|c|c|c|c|c|c|}
\hline \multirow{2}{*}{$\begin{array}{l}\text { Technical } \\
\text { Parameters }\end{array}$} & \multicolumn{3}{|c|}{ Penetration (mm) } & \multirow{2}{*}{$\begin{array}{l}\text { Softening } \\
\text { Point }\left({ }^{\circ} \mathrm{C}\right)\end{array}$} & \multirow{2}{*}{$\begin{array}{c}10^{\circ} \mathrm{C} \\
\text { Ductility }(\mathrm{cm})\end{array}$} & \multirow{2}{*}{$\begin{array}{c}5^{\circ} \mathrm{C} \text { Ductility } \\
\text { (cm) }\end{array}$} & \multirow{2}{*}{$\begin{array}{l}\text { Penetration } \\
\text { Index }\end{array}$} & \multirow{2}{*}{$\begin{array}{l}135^{\circ} \mathrm{C} \text { Apparent } \\
\text { Viscosity (mpa } \cdot \text { s) }\end{array}$} \\
\hline & $15^{\circ} \mathrm{C}$ & $25^{\circ} \mathrm{C}$ & $30^{\circ} \mathrm{C}$ & & & & & \\
\hline base asphalt & 27.5 & 81.3 & 132.6 & 44.2 & 45.7 & 6.3 & -0.87 & 485.3 \\
\hline $1 \%$ NHSS-asphalt & 26.8 & 71.5 & 113.9 & 47 & 20.9 & 6.5 & -0.32 & 721.3 \\
\hline $3 \%$ NHSS-asphalt & 28.4 & 71.2 & 106.9 & 48.6 & 17 & 6.6 & 0.24 & 2219.6 \\
\hline $5 \%$ NHSS-asphalt & 24.0 & 68.4 & 105.9 & 50 & 12.8 & 6.1 & -0.52 & 7455.7 \\
\hline
\end{tabular}

The results show that the addition of NHSS modifiers improves some properties of the base asphalt. The softening point value, $5{ }^{\circ} \mathrm{C}$ ductility value, PI value, and $135{ }^{\circ} \mathrm{C}$ apparent viscosity value of $3 \%$ NHSS-asphalt are greater than $1 \%$ NHSS-asphalt and base asphalt, and the softening point value, $135{ }^{\circ} \mathrm{C}$ apparent viscosity of $5 \%$ NHSS-asphalt are greater than $3 \%$ NHSS-asphalt. Thus, considering that the more the additive is added, the greater the cost is, and the improvement of the overall performance, $3 \%$ NHSS was subjectively identified as the optimum content for base asphalt.

The optimum bitumen content of NHSS modified asphalt concrete (NHSS-AC) was determined by Marshall test according to Chinese specifications for design of highway asphalt pavement (JTG D50-2006). Four asphalt mixes were used-4.5\%, 5.0\%, 5.5\%, and 6.0\%—and the NHSS-AC were prepared using the standard Marshall mix design procedure with 75 blows on each side of the cylindrical specimens. The Marshall stability (MS), flow (FL), volume of air voids (VV), and voids filled with asphalt (VFA) values of the mixtures with different asphalt content were obtained to determine the optimum asphalt content (OBC) of NHSS-AC. The optimum modified asphalt content was found to be $5.7 \%$ for the control mixture. In this study, all NHSS-AC samples were made with $5.7 \%$ modified asphalt content in order to maintain consistency throughout the research. Moreover, base asphalt concrete (AC) was prepared for the same tests as a comparative, and the optimum asphalt content was found to be $5.01 \%$ for the control mixture. The reason why the OBC of NHSS-AC is higher than AC 
may be that some of the NHSS has chemically reacted with the asphalt, and the other part of the NHSS and the asphalt are simply physically blended, the physically blended NHSS acts as a mineral powder, so the OBC of NHSS-AC is higher than AC.

\section{Laboratory Tests}

\section{1. freeze-soak-scour Cycle Test}

In this paper, a laboratory freeze-soak-scour cycle test is designed to simulate the actual condition of asphalt pavement during spring-thawing season. Pavement Material Dynamic Water Scouring Tester (2014, Suzhou Zhixi Environmental Test Equipment Co., Ltd., Suzhou, China) and High-Low Temperature Experimental Box (2015, Changchun, China) are applied in the laboratory freeze-soak-scour cycle test, as shown in Figures 4 and 5.

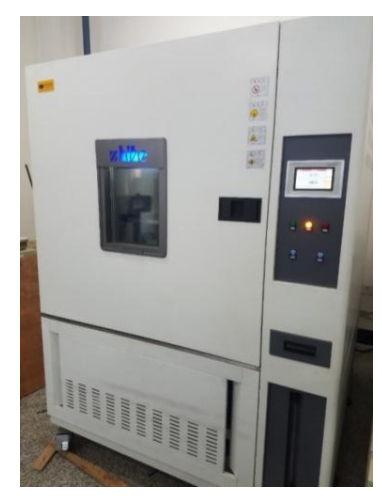

Figure 4. High-Low Temperature Experimental Box.
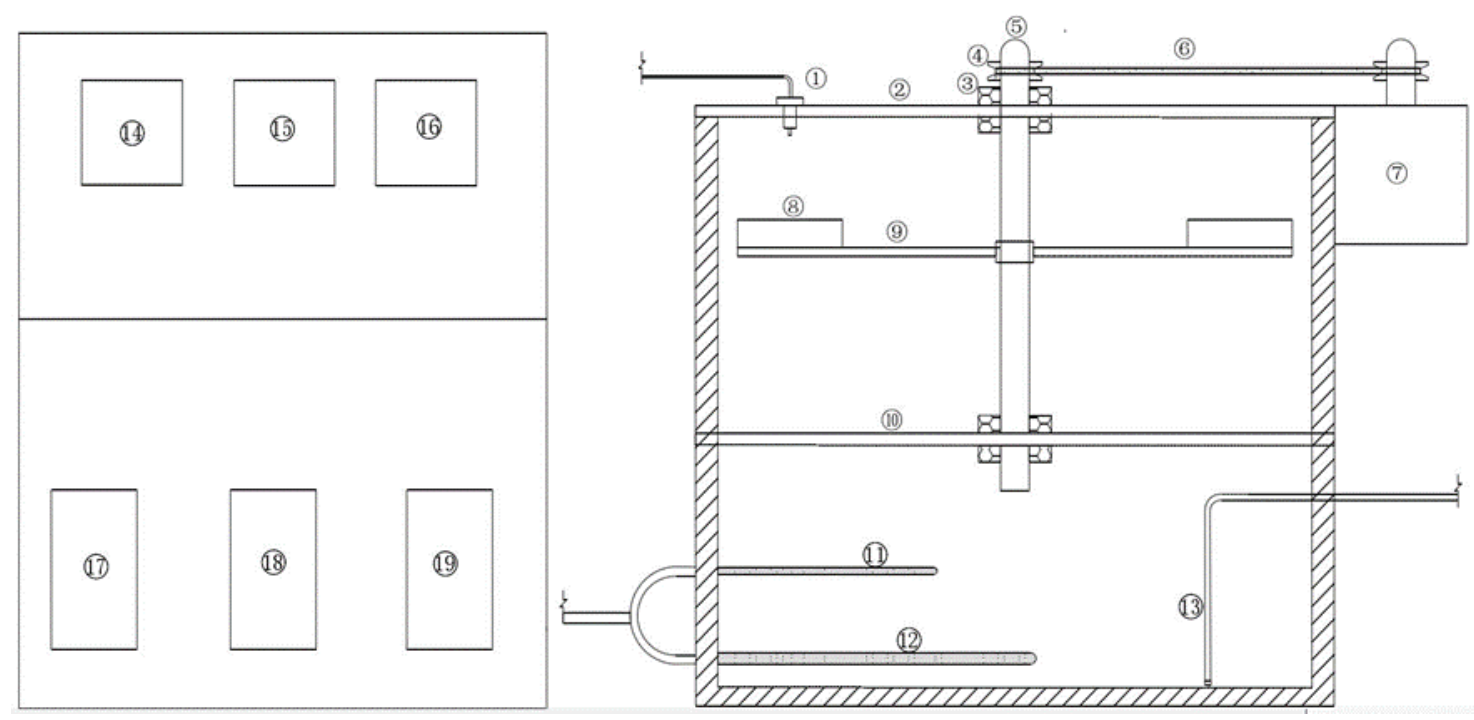

Figure 5. Pavement material dynamic water scouring tester: (1) water gun; (2) support plate; $(3,10)$ bearing; (4) pulley; (5) disk fixed axis; (6) belt; (7) motor; (8) Marshall samples fixed ring; (9) disk; (11) temperature sensor; (12) U shape heating tube; (13) pump intake pipe; (14) temperature control dial; (15) scouring force control dial; (16) disk speed control dial; (17-19) pump and its attached equipment.

The Pavement Material Dynamic Water Scouring Tester is self-developed to simulate the dynamic water scouring phenomenon of saturation pavement, as shown in Figure 5. The main parameters of the test system are the pressure of the water gun, the speed of the disk and scouring time. In order to establish the connection between the laboratory scouring test and the actual condition of pavement, 
a piezoresistive dynamic water pressure sensor is embedded in the Hui-wu expressway (in Songyuan, Jilin, China) to collect the dynamic water scour pressure of pavement, thus adjusting the pressure of water gun and the rotating speed of the disk to realize the laboratory scouring test. The details of a freeze-soak-scour cycle test is described below.

First, the specimens were treated by vacuum saturation in $97.3 \mathrm{kPa}$ for $15 \mathrm{~min}$ and submerged in a container containing water, then the container with specimens were placed in the High-Low Temperature Experimental Box at $-15^{\circ} \mathrm{C}$ and frozen $12 \mathrm{~h}$.

Then, the specimens were soaked in water at $15^{\circ} \mathrm{C}$ for $12 \mathrm{~h}$ through controlling the High-Low Temperature Experimental Box.

Finally, the specimens were removed from the container and placed in the Pavement Material Dynamic Water Scouring Tester for dynamic water test. The pressure of the water gun is set to $2.56 \mathrm{Mpa}$, the speed of the disk is set to $420 \mathrm{rad} / \mathrm{min}$, and the scouring time of one cycle is $4.8 \mathrm{~min}$.

As described above, a complete freeze-soak-scour cycle is completed. Then, after 5, 10, 15, and 20 freeze-soak-scour cycles, damaged AC and NHSS-AC specimens were collected for performance testing to explore the influence of NHSS in asphalt concrete under freeze-soak-scour cycles. Three single factor tests were designed to explore the attenuation law of properties of NHSS-AC with the soaking cycle, freezing cycle, and scouring cycle acting seperately.

\subsection{Durability and Property Test of the Mixture}

The value of voids content and weight loss ratio is used to evaluate the durability of asphalt mixture before and after freeze-soak-scour cycles according to Chinese standards JTG T0705-2011. Marshall test, $-10{ }^{\circ} \mathrm{C}$ splitting test and freeze-soak-scour splitting test were applied to measure the pavement performance of asphalt mixture under freeze-soak-scour cycles. The Marshall test was conducted to measure the high-temperature mechanical properties of the mixture according to Chinese standards JTG T0709-2011. A $-10{ }^{\circ} \mathrm{C}$ splitting test was conducted to assess the capacity of asphalt pavement to bear dynamic loads at low temperature according to JTG T0716-2011. A freeze-soak-scour splitting test was conducted to evaluate water stability of asphalt mixture based on modified freeze-thaw splitting test in accordance with JTG T0729-2011. The freeze-soak-scour splitting tensile strength $\left(\mathrm{R}_{\mathrm{FTn}}\right)$ and freeze-soak-scour splitting tensile ratio $\left(\mathrm{TSR}_{\mathrm{n}}\right)$ are principal mechanical parameters, which are measured in this test. Specimens subjected to $n$ times of freeze-soak-scour cycles $(n=0$, $5,10,15,20)$ were immersed in water bath at $25^{\circ} \mathrm{C}$ for $2 \mathrm{~h}$, and the loading with a constant rate of compression of $50 \mathrm{~mm} / \mathrm{min}$ was applied. $\mathrm{R}_{\mathrm{FTn}}$ and $\mathrm{TSR}_{\mathrm{n}}$ were calculated as follows.

$$
\begin{gathered}
\mathrm{R}_{\mathrm{FTn}}=0.006287 \mathrm{P}_{\mathrm{FTn}} / \mathrm{h}_{\mathrm{n}} \\
\mathrm{TSR}_{\mathrm{n}}=\frac{\mathrm{R}_{\mathrm{FT} 0}}{\mathrm{R}_{\mathrm{FTn}}}
\end{gathered}
$$

where $\mathrm{P}_{\mathrm{FTn}}$ is the maximum load-bear of specimens subjected to $\mathrm{n}$ times of freeze-soak-scour cycles $(\mathrm{N}, \mathrm{n}=0,5,10,15,20)$ and $\mathrm{h}$ is the The height of specimen subjected to $\mathrm{n}$ times of freeze-soak-scour cycles $(m m, n=0,5,10,15,20)$.

\section{Results and Discussion}

\subsection{Effect of freeze-soak-scour Cycles on Properties of NHSS-AC}

As it is shown in Figures 6 and 7, the voids content of the two mixtures gradually increases as the number of freeze-soak-scour cycles increases. After 20 freeze-soak-scour cycles, the void content of AC is already in line with the Chinese specification (the voids content of $\mathrm{AC}<5 \%$ ), and NHSS-AC is still within the standard range. This is because the adhesion of NHSS modified asphalt and aggregate is greater than that of base asphalt and aggregate. Therefore, the voids content change ratio of NHSS-AC is significantly lower than that of AC after multiple cycles, so NHSS-AC has better durability. 


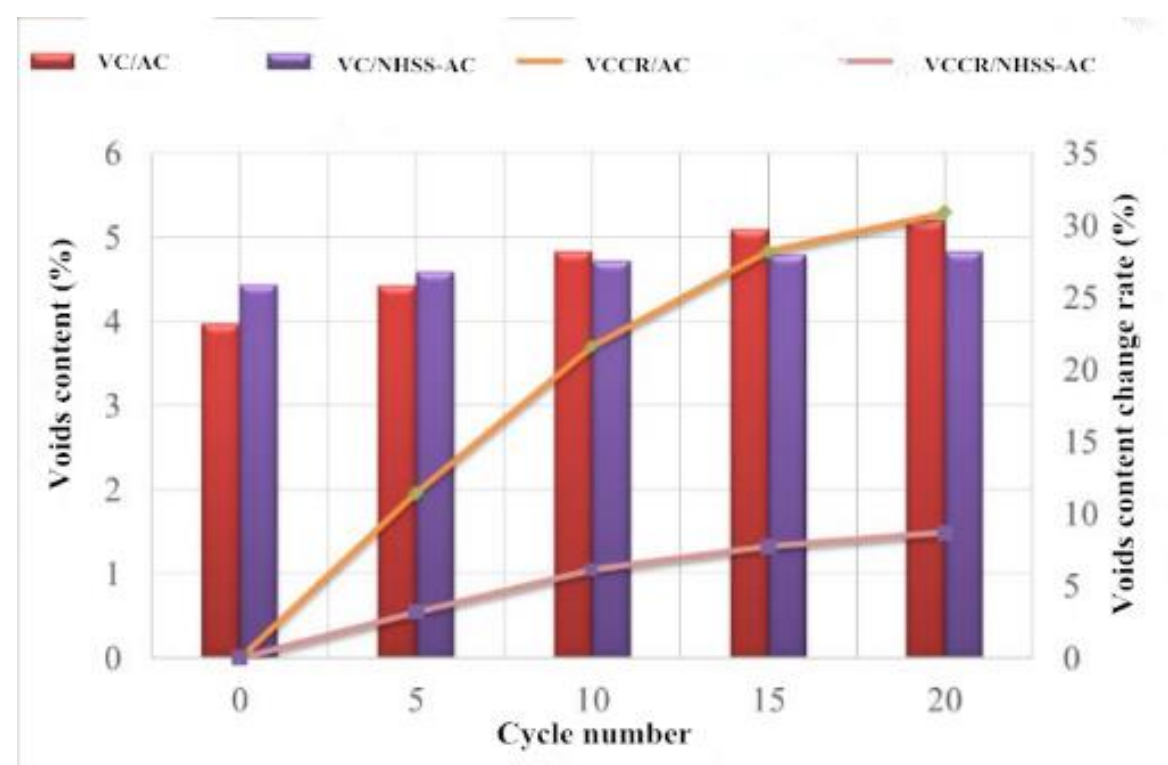

Figure 6. Void content changes of mixtures under freeze-soak-scour cycles.

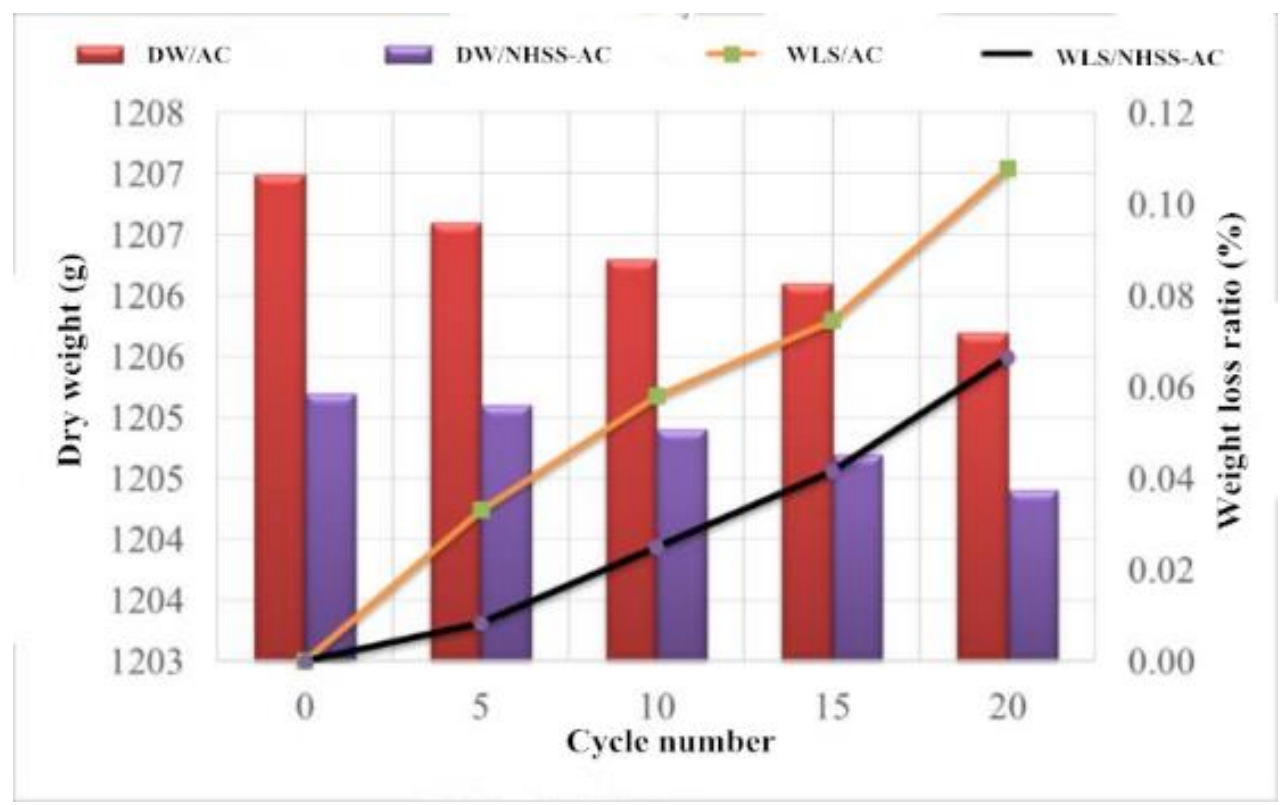

Figure 7. Weight loss ratio changes of mixtures under freeze-soak-scour cycles.

It can be seen from Figure 7 that as the number of cycles increases, the weight loss ratio of the two mixtures gradually increases, indicating that the loose fine aggregate of pavement is taken away by the wheel with the increase of freeze-soak-scour cycle in the spring-thawing season, which leads to the reduction of quality of mixtures and the increase of the weight loss ratio of mixtures. Moreover, the NHSS modified asphalt has a better bond strength with the aggregate than the base asphalt so that the weight loss ratio of NHSS-AC is always smaller than the AC after different freeze-soak-scour cycles.

As it is shown in Figure 8, Marshall stability of mixtures decreases with increasing freeze-soak-scour cycles, and the Marshall stability of the AC has been lower than Chinese specification after 15 cycles (Marshall stability of AC $\geq 8.0 \mathrm{KN}$ ). However, the Marshall stability of the NHSS-AC remained within the scope of the Chinese specification after 20 cycles. The Marshall stability loss ratio of NHSS-AC is far less than that of AC under the same cycles. It can be seen that NHSS has 
certain advantages in improving the high temperature mechanical properties of asphalt mixtures in spring-thawing season.

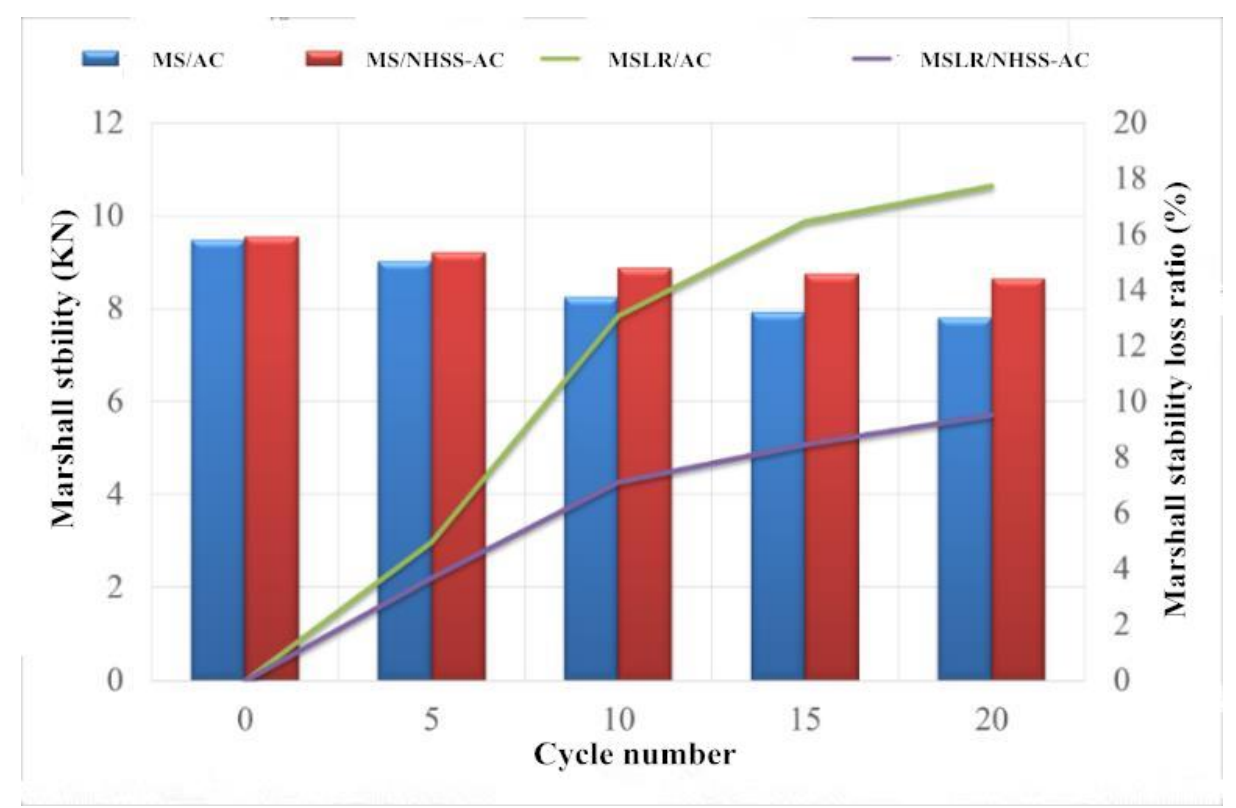

Figure 8. Marshall stability changes of mixtures under freeze-soak-scour cycles.

The data of $-10{ }^{\circ} \mathrm{C}$ splitting test is shown in Table 5. The splitting tensile strength and destruction tensile strain are continuously reduced with the increase of the number of cycles. After 20 cycles, the splitting tensile strength of AC decreased by $9.7 \%$ and destruction tensile strain decreased by $10.3 \%$. By contrast, the splitting tensile strength of NHSS-AC decreased by $8.3 \%$ and destruction tensile strain decreased by $10.7 \%$. Thus, the low temperature mechanical property of NHSS-AC is better than that of $\mathrm{AC}$ in freeze-thawing season. The change of destruction stiffness modulus is disordered, because the attenuation curve of splitting tensile strength and destruction tensile strain is not consistent.

Table 5. Results of $-10{ }^{\circ} \mathrm{C}$ splitting test.

\begin{tabular}{ccccccc}
\hline Mixture Type & Number of Cycles & $\mathbf{0}$ & $\mathbf{5}$ & $\mathbf{1 0}$ & $\mathbf{1 5}$ & $\mathbf{2 0}$ \\
\hline \multirow{3}{*}{ AC } & Splitting tensile strength $(\mathrm{Mpa})$ & 4.02 & 3.57 & 3.78 & 3.71 & 3.63 \\
& Destruction tensile strain $(\mu \varepsilon)$ & 2.06 & 2.00 & 1.97 & 1.88 & 1.85 \\
& Destruction stiffness modulus $(\mathrm{Mpa})$ & 3361 & 3330 & 3305 & 3397 & 3383 \\
\hline \multirow{3}{*}{ NHSS-AC } & Splitting tensile strength $(\mathrm{Mpa})$ & 4.33 & 4.22 & 4.15 & 4.07 & 3.97 \\
& Destruction tensile strain $(\mu \varepsilon)$ & 2.27 & 2.18 & 2.12 & 2.09 & 2.03 \\
& Destruction stiffness modulus $(\mathrm{Mpa})$ & 3282 & 3330 & 3365 & 3353 & 3369 \\
\hline
\end{tabular}

The result of freeze-soak-scour splitting test is shown in Figure 9. It illustrates that the $R_{\mathrm{FTn}}$ of the mixtures continuously reduced with the increase of the number of cycles, and the $R_{\mathrm{FTn}}$ of the AC drastically attenuated during the first five cycles, and the decay rate tends to be slow after that. The $\mathrm{TSR}_{\mathrm{n}}$ of NHSS-AC is lower than that of AC at various points in the freeze-soak-scour cycles, and the TSR $\mathrm{n}_{n}$ of NHSS-AC is $5 \%$ higher than the AC. Thus, the water stability of NHSS-AC is better than that of $\mathrm{AC}$ in freeze-thawing season. 


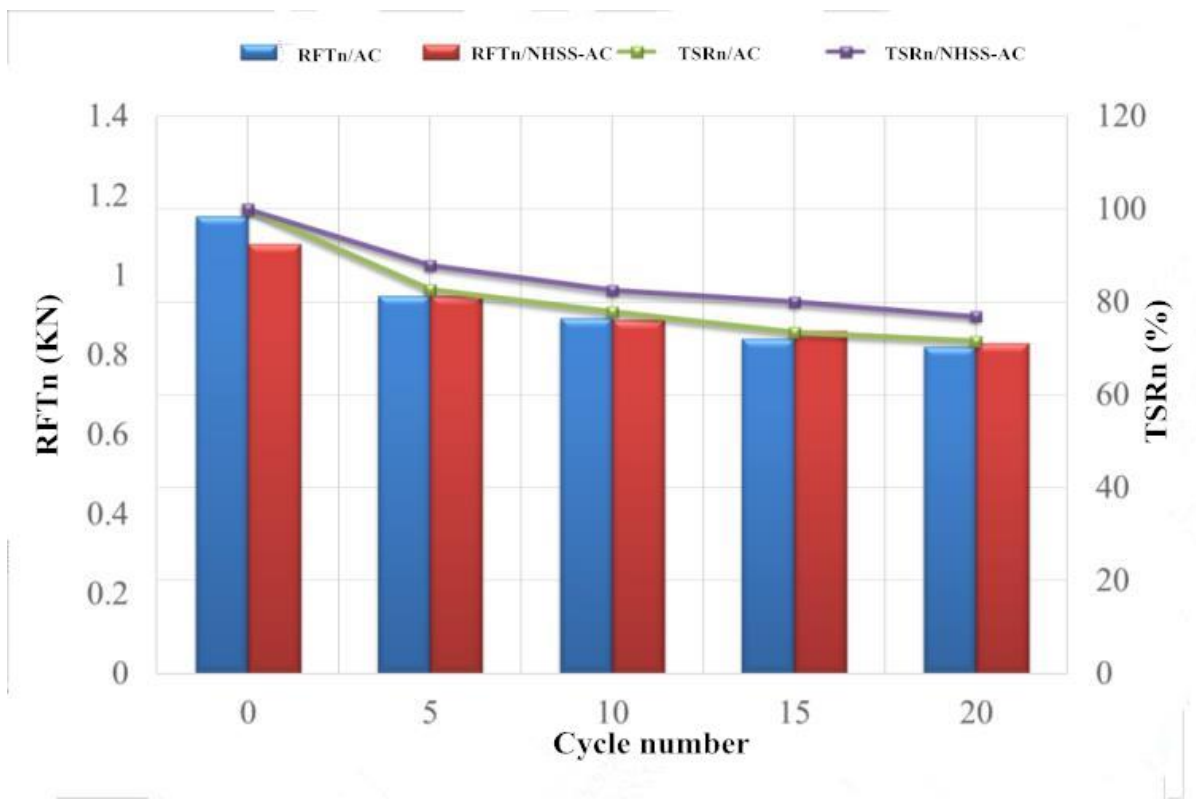

Figure 9. TSRn changes of mixtures under freeze-soak-scour cycles.

Overall, after 15 or 20 freeze-soak-scour cycles, the normal asphalt mixture cannot meet the requirements of specifications, and the NHSS modified asphalt mixture still meet the requirements of the specifications, which indicates that the NHSS modified can effectively improve the ability of asphalt concrete to resist the spring environment.

The price of normal asphalt is about $3000 \mathrm{rmb} / \mathrm{t}$, and the price of NHSS modified asphalt is about $3300 \mathrm{rmb} / \mathrm{t}$. The comprehensive unit price analysis of mechanical paving NHSS modified asphalt concrete of $7 \mathrm{~cm}$ thick is as follows. (a) Artificial cost: $2.1 \mathrm{rmb} / \mathrm{cm}^{2}$; (b) Materials cost (including main material and auxiliary material): $97.7 \mathrm{rmb} / \mathrm{cm}^{2}$; (c) Mechanical cost: $2.5 \mathrm{rmb} / \mathrm{cm}^{2}$; (d) Other cost (including safe and civilized construction costs, fees, and taxes): $7.4 \mathrm{rmb} / \mathrm{cm}^{2}$. The total cost of NHSS modified asphalt concrete is $109.7 \mathrm{rmb} / \mathrm{cm}^{2}$, and the total cost of normal asphalt concrete is $102 \mathrm{rmb} / \mathrm{cm}^{2}$. The cost of mechanical paving NHSS modified asphalt concrete of $7 \mathrm{~cm}$ thick is $7.6 \%$ higher than normal asphalt concrete. Considering the ability of NHSS modified asphalt to improve the durability and the property of the asphalt concrete in spring-thawing season, an increase of $7.6 \%$ of the cost is still acceptable.

Establishment of the freeze-soak-scour Damage Model of NHSS-AC based on the Logistic Judgment Model

The logistic judgment model is a set of nonlinear regular regression models which are mainly used to describe and infer the relationship between two or more classified dependent variables and a set of variables. Compared with multiple linear regression, logistic regression has many unique advantages. The model does not require the normality and homogeneity of the data variables in the calculation, nor does it limit the specific type of the independent variable, and its statistical coefficient has strong interpretability, so that the logistic regression models can be widely used in metrology research. In this paper, the deterioration process of NHSS-AC under freeze-soak-scour cycles was studied based on logistic judgment model.

The equation of logistic curve is used to study the increasing process of the population by biologist P. F. Verhulst initially. The equation is expressed as

$$
\mathrm{y}=\frac{K}{1+a e^{-b t}}
$$


The first derivative of the above equation can be found. The resulting equation is the growth velocity function of the described object.

$$
\mathrm{v}(\mathrm{t})=\frac{d y}{d t}=\frac{K a b e^{-b t}}{\left(1+a e^{-b t}\right)^{2}}
$$

The growth process of the logistic curve is slow-fast-slow. The first derivative of the growth velocity function can be found, then let the result be 0 .

$$
\frac{d v(t)}{d t}=\frac{K a b e^{-b t}\left(a b e^{-b t}-b\right)}{\left(1+a e^{-b t}\right)^{3}}=0
$$

We can get

$$
t=\frac{\ln a}{b}
$$

So, when $t=\frac{\ln a}{b}$, the object is at the peak of the growth.

Then find the second derivative of the growth velocity function, then let the result be 0 .

$$
\frac{d^{2} v(t)}{d^{2} t}=\frac{K a b^{3} e^{-b t}\left(1-4 a b e^{-b t}+a^{2} e^{-2 b t}\right)}{\left(1+a e^{-b t}\right)^{4}}=0
$$

We can get that

$$
\begin{aligned}
& t_{1}=\frac{\ln a-1.317}{b} \\
& t_{2}=\frac{\ln a+1.317}{b}
\end{aligned}
$$

Re-number the three key points

$$
\begin{gathered}
t_{1}=\frac{\ln a-1.317}{b} \\
t_{2}=\frac{\ln a}{b} \\
t_{3}=\frac{\ln a+1.317}{b}
\end{gathered}
$$

$t_{1}$ is the initial time point of the growth peak of the study, $t_{2}$ is the peak, $t_{3}$ is the end. $\varphi_{i}$ is used as the damage coefficient of the performance of the mixtures after the freeze-soak-scour cycle, then

$$
\varphi_{\mathrm{i}}=1-\frac{\theta_{\mathrm{i}}}{\theta_{0}}
$$

In the formula, $\theta_{\mathrm{i}}$ is the test index of specimens after $\mathrm{i}$ cycles.

According to the tests, the voids content is used to evaluate the durability of mixtures, the Marshall stability is used to evaluate the high-temperature mechanical property of mixtures, $-10{ }^{\circ} \mathrm{C}$ splitting tensile strength and the destruction tensile strain are used to evaluate the low-temperature mechanical property, the freeze-soak-scour splitting tensile ratio is used to evaluate the water stability. If two indexes are needed to evaluate the damage of a certain mechanical property of mixtures, the damage coefficient takes the mean of the damage coefficient of two indexes

For the convenience of analysis, the damage process represented by the logistic curve equation is transformed into

$$
\varphi=\frac{\mathrm{A}_{\min }-\mathrm{A}_{\max }}{1+\left(\frac{\mathrm{x}}{\mathrm{x}_{0.5}}\right)^{\mathrm{a}}}+\mathrm{A}_{\max }
$$


In the formula, $A_{\min } / A_{\max }$ is the $\min / \max$ value of the regression curve, $x_{0.5}$ is the value of $x$ when $\varphi=0.5 \mathrm{~A}_{\max }$. Then according to the form of the curve, $\mathrm{A}_{\max }$ can be used to evaluate the damage degree of the properties of asphalt cement, and then $\mathrm{x}_{0.5}$ is used to evaluate the damage speed of the properties of mixture.

For the initial condition of the model, when the cycle is not processed, the number of cycles in the damage model is zero, and the growth rate of the damage rate is also zero. Thus, $A_{\min }=0$ and the model is transformed into

$$
\varphi=\frac{-\mathrm{A}_{\max }}{1+\left(\frac{\mathrm{x}}{\mathrm{x}_{0.5}}\right)^{\mathrm{a}}}+\mathrm{A}_{\max }
$$

For the convenience of the following expression, the above formula is written as

$$
y=\frac{-a}{1+\left(\frac{x}{c}\right)^{b}}+a
$$

Then, the first derivative of the damage velocity model is calculated and let it be 0 .

$$
\mathrm{v}^{\prime}(\mathrm{x})=\frac{\frac{\mathrm{ab}}{\mathrm{c}^{\mathrm{b}}} \mathrm{x}^{\mathrm{b}-2}\left[\mathrm{~b}-1-\frac{\mathrm{b}+1}{\mathrm{c}^{\mathrm{b}}} \mathrm{x}^{\mathrm{b}}\right]}{\left(1+\frac{\mathrm{x}^{\mathrm{b}}}{\mathrm{c}^{\mathrm{b}}}\right)^{3}}=0
$$

Then the second derivative of the damage velocity model is calculated and let it be 0 .

$$
\begin{aligned}
& \mathrm{V}^{\prime \prime}(\mathrm{x}) \\
& =\frac{\frac{\mathrm{ab}(\mathrm{b}+1)^{2}}{\mathrm{c}^{2 b}} x^{2 b}-\frac{\mathrm{ab}(\mathrm{b}-1)^{2}-a b(b+1)(2 b-1) c^{\mathrm{b}}-3 a b^{2}(\mathrm{~b}-1)}{\mathrm{c}^{2 b}} x^{\mathrm{b}}+\frac{\mathrm{ab}(\mathrm{b}-1)^{2}}{\mathrm{c}^{\mathrm{b}}}}{\left(1+\frac{\mathrm{x}^{\mathrm{b}}}{\mathrm{c}^{\mathrm{b}}}\right)^{4} x^{\mathrm{b}-2}} \\
& =0
\end{aligned}
$$

Let

$$
A=\frac{a b(b+1)^{2}}{c^{2 b}}, B=\frac{a b(b-1)^{2}-a b(b+1)(2 b-1) c^{b}-3 a b^{2}(b-1)}{c^{2 b}}, C=\frac{a b(b-1)^{2}}{c^{b}}
$$

The result can be

$$
x_{0}=\sqrt[b]{c^{b} \cdot \frac{b-1}{b+1}}, x_{1}=\sqrt[b]{\frac{-B-\sqrt{B^{2}-4 A C}}{2 A}}, x_{2}=\sqrt[b]{\frac{-B+\sqrt{B^{2}-4 A C}}{2 A}}
$$

According to the analysis above, it can be known that $\mathrm{x}_{1}$ is the initial time point when some properties of the mixture get into the growth peak period, $x_{0}$ is the peak time and $x_{2}$ is the end. According to the experimental data, the damage degree of the pavement properties of mixtures can be got after different cycles. They are shown in Figure 10. 


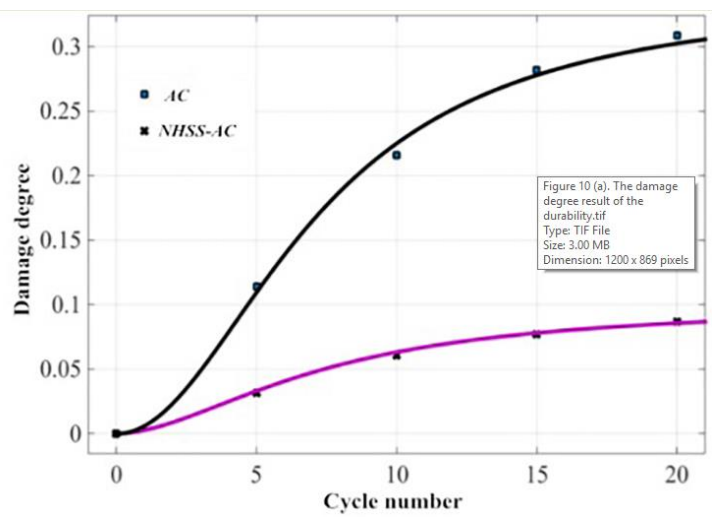

(a) Damage degree result of the durability.

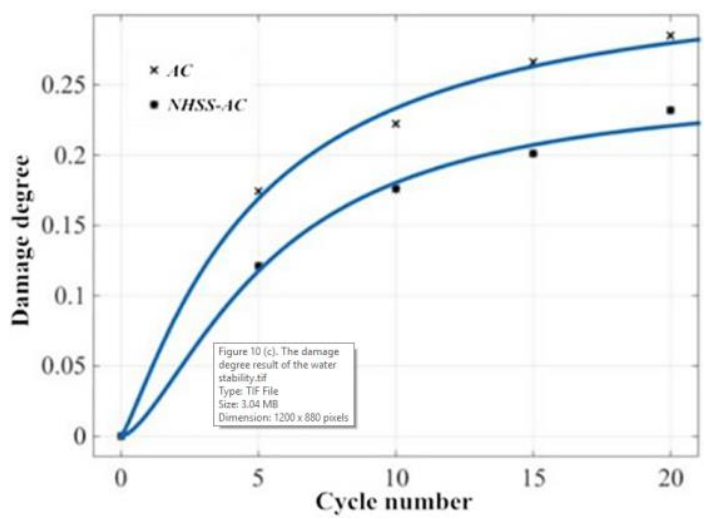

(c) Damage degree result of the water stability.

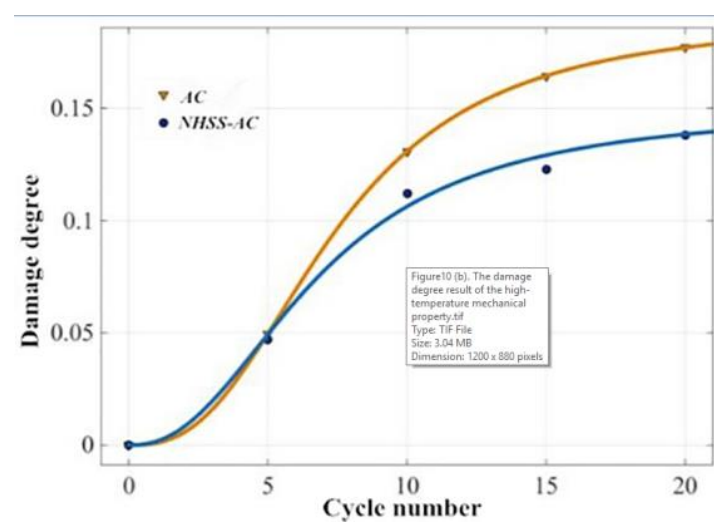

(b) Damage degree result of the high-temperature mechanical property.

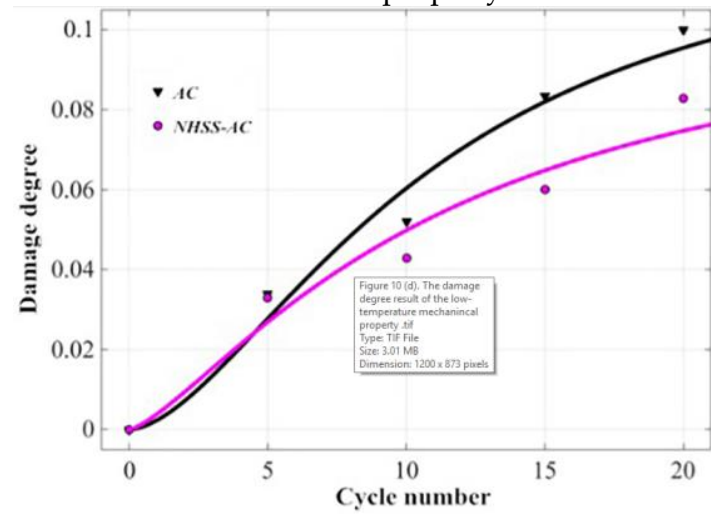

(d) Damage degree result of the low-temperature mechanical property.

Figure 10. Damage degree result of the various properties of the AC and NHSS-AC.

The regression equation of the damage model and the corresponding value of each model is shown in Table 6. The freeze-thaw-scour damage model is effective, because all $\mathrm{R}^{2}$ of the regression equation are above 0.95 .

Table 6. Fitting result of the logistic damage model.

\begin{tabular}{|c|c|c|c|c|c|c|c|c|}
\hline Mixture & Pavement Property & Logistic Damage Model & $\mathrm{SS}_{\mathrm{e}}$ & $\mathbf{R}^{2}$ & $\mathbf{R}_{\mathrm{MSE}}$ & $\mathrm{x}_{0}$ & $x_{1}$ & $\mathrm{x}_{2}$ \\
\hline \multirow{4}{*}{$\mathrm{AC}$} & Durability & $\varphi=-\frac{0.34}{1+\left(\frac{x}{7.2}\right)^{2.044}}+0.34$ & $1.5 \times 10^{-4}$ & 0.9976 & 0.0063 & 4.3 & 0.35 & 7.3 \\
\hline & $\begin{array}{l}\text { High temperature } \\
\text { mechanical property }\end{array}$ & $\varphi=-\frac{0.19}{1+\left(\frac{x}{7.4}\right)^{2.644}}+0.19$ & $6.7 \times 10^{-8}$ & 0.9999 & 0.0011 & 5.5 & 0.51 & 7.9 \\
\hline & Water stability & $\varphi=-\frac{0.33}{1+\left(\frac{x}{4.8}\right)^{1.203}}+0.33$ & $1.9 \times 10^{-4}$ & 0.9964 & 0.0069 & 0.7 & 0.03 & 3.4 \\
\hline & $\begin{array}{l}\text { Low temperature } \\
\text { mechanical property }\end{array}$ & $\varphi=-\frac{0.13}{1+\left(\frac{x}{10.9}\right)^{1.674}}+0.13$ & $1.3 \times 10^{-4}$ & 0.9796 & 0.0057 & 4.8 & 0.21 & 10.1 \\
\hline \multirow{4}{*}{ NHSS-AC } & Durability & $\varphi=-\frac{0.10}{1+\left(\frac{x}{7.4}\right)^{1.797}}+0.10$ & $9 \times 10^{-6}$ & 82 & 0.0015 & 3.7 & 0.26 & 7.1 \\
\hline & $\begin{array}{l}\text { High temperature } \\
\text { mechanical property }\end{array}$ & $\varphi=-\frac{0.15}{1+\left(\frac{x}{6.8}\right)^{2.31}}+0.15$ & $8 \times 10^{-5}$ & 0.9941 & 0.0045 & 4.6 & 0.43 & 7.1 \\
\hline & Water stability & $\varphi=-\frac{0.25}{1+\left(\frac{x}{5.4}\right)^{1.546}}+0.25$ & $2 \times 10^{-4}$ & 40 & 0.0070 & 2.0 & 0.15 & 4.8 \\
\hline & $\begin{array}{l}\text { Low temperature } \\
\text { mechanical property }\end{array}$ & $\varphi=-\frac{0.11}{1+\left(\frac{x}{11.5}\right)^{1.354}}+0.11$ & $1.7 \times 10^{-4}$ & 0.9547 & 0.0066 & 2.8 & 0.08 & 9.1 \\
\hline
\end{tabular}

where SSe is residual sum of squares, $R^{2}$ is determination coefficient, and $R_{M S E}$ is root-mean-square error

In order to compare the model parameters and analyze physical meaning, the contrast figure was given in Figure 11. 


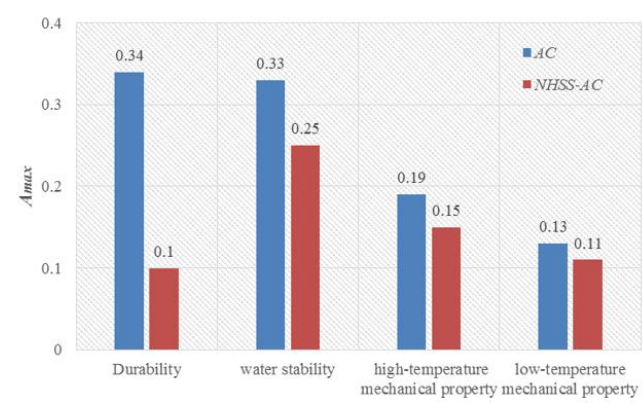

(a) Maximum damage drgree (Amax)

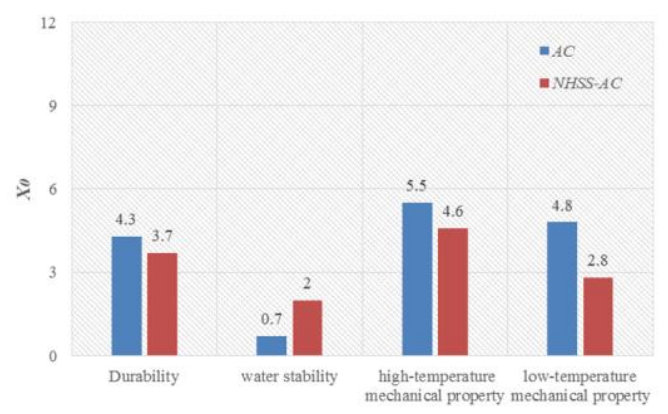

(c) Cycle number responding to the growth peak of damage degree $\left(\mathrm{X}_{0}\right)$

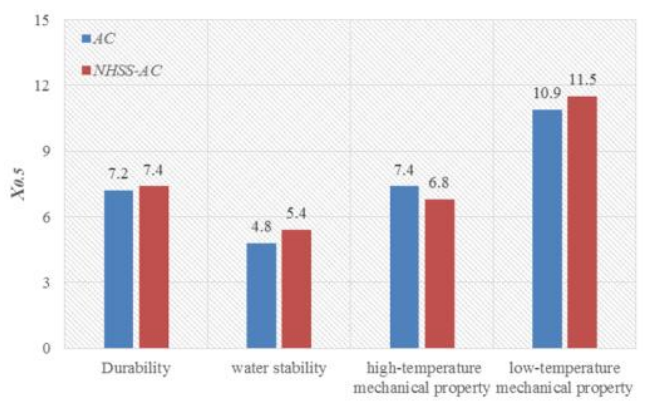

(b) Cycle number responding to half of maximum damage degree $\left(\mathrm{X}_{0.5}\right)$

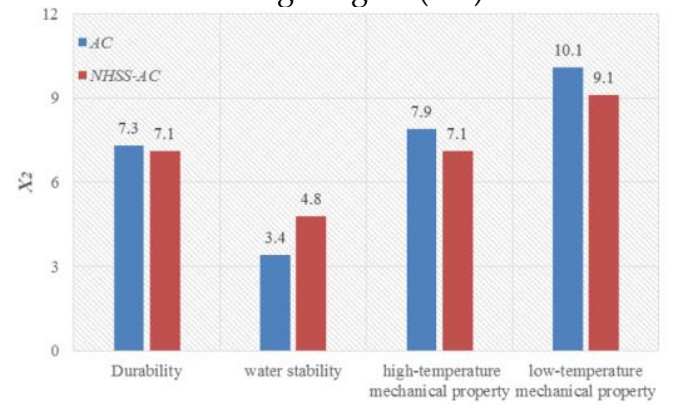

(d) Cycle number responding to the end of damage degree growing peak $\left(\mathrm{X}_{2}\right)$

Figure 11. Parameters of the Logistic damage model.

From Figure 11a, it can be seen that after 20 freeze-soak-scour cycles, the durability and water stability are the most damaged of the four properties of the AC, reaching 0.34 and 0.33 respectively. The water stability and the high-temperature mechanical property are the most damaged of the four properties of the NHSS-AC, reaching 0.25 and 0.15 respectively. The difference of the damage degree of the low-temperature mechanical property of AC and NHSS-AC is small. The damage degree of durability and mechanical property of NHSS-AC are less than that of AC under freeze-soak-scour cycles, indicating that the NHSS-AC has significant effects on preventing and controlling the damage of the pavement in spring-thawing season.

Figure $11 \mathrm{~b}$ shows that water stability, high-temperature mechanical property, durability and low-temperature mechanical property of mixtures were ranked by $X_{0.5}$ from small to big. It is known that under the action of freeze-soak-scour cycles, the damage rate of water stability is the fast, while that of low-temperature mechanical property is the slowest. Thus, the damage degree of water stability of mixtures is the largest and the damage speed is the fastest, so the moisture damage of pavement is most likely to occur in the spring-thawing season. The index $X_{0.5}$ of AC and NHSS-AC are almost identical, indicating that the incorporation of NHSS does not change the pattern of the damage process of the pavement in spring-thawing season.

From Figure 11a,b,d, it can be known that the damage rate of the water stability of the mixture reached the peak first and it was the first to end the damage peak period and enter the stage of stable growth. The index $\mathrm{X}_{0}$ of NHSS-AC is greater than that of AC except water stability.

\subsection{Analysis of Three Kinds of Damage Factors of NHSS-AC in Spring-Thawing Season Based on the Gray Rational Degree Theory}

\subsubsection{Soaking Cycles Test}

A soaking cycle takes $12 \mathrm{~h}$ at a water temperature of $15^{\circ} \mathrm{C}$. After $0,5,10,15$, and 20 soaking cycles, damaged NHSS-AC specimens were collected for the durability and performance test. The data after the tests is shown in Table 7. 
Table 7. Variation of NHSS-AC parameters under soak cycle.

\begin{tabular}{|c|c|c|c|c|c|c|c|}
\hline \multirow[b]{2}{*}{$\begin{array}{l}\text { Number } \\
\text { of Cycle }\end{array}$} & \multirow[b]{2}{*}{$\begin{array}{c}\text { Voids } \\
\text { Content } \\
(\%)\end{array}$} & \multirow[b]{2}{*}{$\begin{array}{c}\text { Weight } \\
\text { Loss Ratio } \\
\text { (\%) }\end{array}$} & \multirow[b]{2}{*}{$\begin{array}{l}\text { Freeze-thaw } \\
\text { Splitting } \\
\text { Tensile } \\
\text { Ratio (\%) }\end{array}$} & \multirow[b]{2}{*}{$\begin{array}{c}\text { Marshall } \\
\text { Stability } \\
\text { (kn) }\end{array}$} & \multicolumn{3}{|c|}{$-10^{\circ} \mathrm{C}$ Splitting Test } \\
\hline & & & & & $\begin{array}{l}\text { Splitting } \\
\text { Tensile } \\
\text { Strength } \\
\text { (Mpa) }\end{array}$ & $\begin{array}{c}\text { Destruction } \\
\text { Tensile } \\
\text { Strain } \\
(\mu \varepsilon)\end{array}$ & $\begin{array}{l}\text { Destruction } \\
\text { Stiffness } \\
\text { Modulus } \\
\text { (Mpa) }\end{array}$ \\
\hline 0 & 4.733 & 0.000 & 100 & 93.5 & 4.32 & 2.27 & 3282 \\
\hline 5 & 4.776 & 0.025 & 89.7 & 8.93 & 4.30 & 2.15 & 3442 \\
\hline 10 & 4.814 & 0.025 & 86.7 & 8.83 & 4.28 & 2.15 & 3422 \\
\hline 15 & 4.861 & 0.034 & 82.6 & 8.78 & 4.24 & 2.12 & 3441 \\
\hline 20 & 4.849 & 0.042 & 80.5 & 8.63 & 4.20 & 2.06 & 3511 \\
\hline
\end{tabular}

\subsubsection{Freezing Cycles Test}

The details of a freezing cycle test are described below. The specimens were treated by vacuum saturation in $97.3 \mathrm{kPa}$ for $15 \mathrm{~min}$ and submerged in a container containing water, then the container with specimens were placed in the High-Low Temperature Experimental Box at $-15^{\circ} \mathrm{C}$ and frozen $12 \mathrm{~h}$. As described above, a complete freezing cycle is completed. Then, after $0,5,10,15$, and 20 freezing cycles, damaged NHSS-AC specimens were collected for the performance test after the frozen specimens were removed and placed in a $15{ }^{\circ} \mathrm{C}$ environment for $6 \mathrm{~h}$. The results are shown in Table 8 .

Table 8. Variation of NHSS-AC parameters under freezing cycle.

\begin{tabular}{|c|c|c|c|c|c|c|c|}
\hline \multirow[b]{2}{*}{$\begin{array}{l}\text { Number } \\
\text { of Cycle }\end{array}$} & \multirow[b]{2}{*}{$\begin{array}{l}\text { Voids } \\
\text { Content } \\
(\%)\end{array}$} & \multirow[b]{2}{*}{$\begin{array}{c}\text { Weight } \\
\text { Loss Ratio } \\
(\%)\end{array}$} & \multirow[b]{2}{*}{$\begin{array}{l}\text { Freeze-thaw } \\
\text { Splitting } \\
\text { Tensile } \\
\text { Ratio (\%) }\end{array}$} & \multirow[b]{2}{*}{$\begin{array}{c}\text { Marshall } \\
\text { Stability } \\
\text { (kn) }\end{array}$} & \multicolumn{3}{|c|}{$-10^{\circ} \mathrm{C}$ Splitting Test } \\
\hline & & & & & $\begin{array}{l}\text { Splitting } \\
\text { Tensile } \\
\text { Strength } \\
\text { (Mpa) }\end{array}$ & $\begin{array}{c}\text { Destruction } \\
\text { Tensile } \\
\text { Strain } \\
(\mu \varepsilon)\end{array}$ & $\begin{array}{l}\text { Destruction } \\
\text { Stiffness } \\
\text { Modulus } \\
\text { (Mpa) }\end{array}$ \\
\hline 0 & 4.009 & 0.000 & 100 & 9.35 & 4.32 & 2.27 & 3282 \\
\hline 5 & 4.207 & 0.025 & 89.4 & 9.02 & 4.28 & 2.18 & 3374 \\
\hline 10 & 4.331 & 0.034 & 85.7 & 8.76 & 4.21 & 2.21 & 3275 \\
\hline 15 & 4.378 & 0.042 & 80.5 & 8.44 & 4.14 & 2.18 & 3267 \\
\hline 20 & 4.425 & 0.050 & 78.8 & 8.21 & 4.04 & 2.15 & 3234 \\
\hline
\end{tabular}

\subsubsection{Scouring Cycles Test}

The scouring cycle test is designed based on Pavement Material Dynamic Water Scouring Tester. The water gun pressure, the speed of the disk, and the scour time are set to $2.56 \mathrm{Mpa}, 420 \mathrm{rad} / \mathrm{min}$, and 4.8 min respectively to realize a scouring cycle. Then, after $0,5,10,15$, and 20 scouring cycles test, damaged NHSS-AC specimens were collected for the durability and performance test. The results are shown in Table 9.

Table 9. Variation of NHSS-AC parameters under scouring cycle.

\begin{tabular}{|c|c|c|c|c|c|c|c|}
\hline \multirow[b]{2}{*}{$\begin{array}{l}\text { Number } \\
\text { of Cycle }\end{array}$} & \multirow[b]{2}{*}{$\begin{array}{c}\text { Voids } \\
\text { Content } \\
(\%)\end{array}$} & \multirow[b]{2}{*}{$\begin{array}{c}\text { Weight } \\
\text { Loss Ratio } \\
\text { (\%) }\end{array}$} & \multirow[b]{2}{*}{$\begin{array}{l}\text { Freeze-thaw } \\
\text { Splitting } \\
\text { Tensile } \\
\text { Ratio }(\%)\end{array}$} & \multirow[b]{2}{*}{$\begin{array}{l}\text { Marshall } \\
\text { Stability } \\
\text { (kn) }\end{array}$} & \multicolumn{3}{|c|}{$-10^{\circ} \mathrm{C}$ Splitting Test } \\
\hline & & & & & $\begin{array}{l}\text { Splitting } \\
\text { Tensile } \\
\text { Strength } \\
\text { (Mpa) }\end{array}$ & $\begin{array}{l}\text { Destruction } \\
\text { Tensile } \\
\text { Strain } \\
(\mu \varepsilon)\end{array}$ & $\begin{array}{l}\text { Destruction } \\
\text { Stiffness } \\
\text { Modulus } \\
\text { (Mpa) }\end{array}$ \\
\hline 0 & 4.370 & 0.000 & 100 & 9.35 & 4.32 & 2.27 & 3282 \\
\hline 5 & 4.474 & 0.008 & 90.6 & 9.32 & 4.31 & 2.24 & 3307 \\
\hline 10 & 4.548 & 0.025 & 85.1 & 9.01 & 4.27 & 2.21 & 3323 \\
\hline 15 & 4.594 & 0.033 & 85.0 & 8.65 & 4.25 & 2.21 & 3304 \\
\hline 20 & 4.678 & 0.042 & 81.5 & 8.58 & 4.22 & 2.18 & 3330 \\
\hline
\end{tabular}




\subsubsection{Analysis of Results Based on the Gray Rational Degree Theory}

The gray rational degree theory focuses on the problems of small samples and poor information which are difficult to solve in probability and statistics and fuzzy mathematics. The theory is based on information coverage, and explores the evolvement rule of things through the action of sequence operators. The main idea of gray rational degree theory is to judge whether the relationship is close according to the similarity of the geometric shape of the sequence curve. The closer the curve develops, the greater the correlation degree between the corresponding sequences will be. The method can provide a quantitative measure for the development and change trend of a system, which is very suitable for the judgment and analysis of dynamic process. The calculation process of grey correlation degree is shown below.

Define the reference sequence and the comparison sequence.

If the reference sequence is set as

$$
X_{0}=\left\{x_{0}(1), x_{0}(2), \cdots \cdots x_{0}(n)\right\}
$$

and the comparison sequence is set as

$$
X_{i}=\left\{x_{i}(1), x_{i}(2), \cdots \cdots x_{i}(n)\right\}
$$

The grey correlation degree value of point $\gamma\left(x_{0}(k), x_{i}(k)\right)$ is calculated as

$$
\gamma\left(x_{0}(k), x_{i}(k)\right)=\frac{\min _{i} \min _{k}\left|x_{0}(k)-x_{i}(k)\right|+\rho \max _{i} \max _{k}\left|x_{0}(k)-x_{i}(k)\right|}{\left|x_{0}(k)-x_{i}(k)\right|+\rho \max _{i} \max _{k}\left|x_{0}(k)-x_{i}(k)\right|}
$$

where $k=1,2, \ldots, \mathrm{n}, \rho$ is the distinguishing coefficient and it value follows the principle of minimum information $\rho \in(0,1)$.

The grey correlation degree $\gamma\left(X_{0}, X_{i}\right)$ between $X_{i}$ and $X_{0}$ is written as

$$
\gamma\left(X_{0}, X_{i}\right)=\frac{1}{n} \sum_{k=1}^{n} \gamma\left(x_{0}(k), x_{i}(k)\right)
$$

A larger grey correlation degree value indicates the reference sequence has more effect on the comparison sequence, and vice versa.

In this paper, the gray rational degree theory was applied to explore the influence of three separate factors on the pavement properties of NHSS-AC in spring-thawing season. The voids content (durability), freeze-soak-scour splitting tensile ratio (water stability), Marshall stability (high temperature mechanical property), $-10{ }^{\circ} \mathrm{C}$ splitting tensile strength (low-temperature mechanical property) of NHSS-AC after 0, 5, 10, 15, and 20 freeze-soak-scour cycles are the systematic characteristic behavior sequence. The same of NHSS-AC with $0,5,10,15$, and 20 soaking cycles, freezing cycle, and scouring cycle act separately are correlation factor sequence. The correlation degree between the systematic characteristic behavior sequence and correlation factor sequences is calculated according to the gray rational degree theory, the results are as shown in Figure 12. 


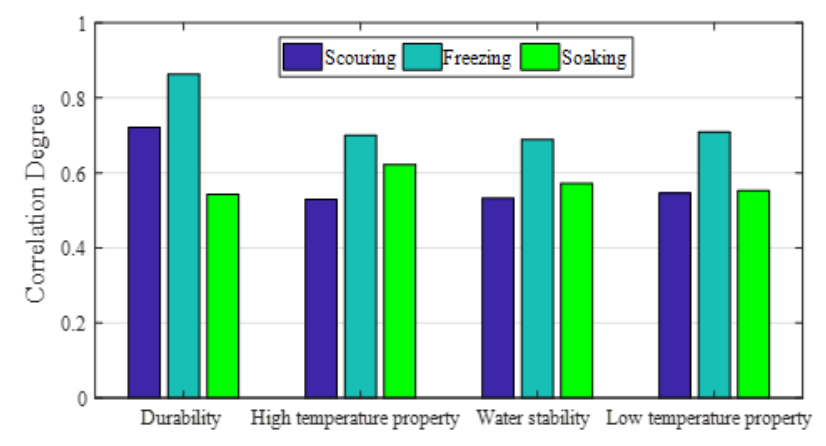

Figure 12. Calculation results of NHSS-AC by the gray rational degree theory.

A larger grey correlation degree value indicates the reference sequence has more effect on the comparison sequence, and vice versa. As is shown in Figure 12, the freezing cycles have a more significant impact on the properties of NHSS-AC compared with the soaking and scouring cycles. The impact of the scouring cycles on the durability of NHSS-AC is more significantly than that of the soaking cycle. The effect of scouring and soaking on low-temperature mechanical property of NHSS-AC under freeze-soak-scour cycles is similar. From the perspective of single factor to analyze, the freezing and scouring factor has the highest correlation degree with the durability of NHSS-AC in spring-thawing season, and the soaking factor has the highest correlation degree with the high-temperature mechanical properties of NHSS-AC in spring-thawing season.

It can be seen that the effect of multiple freezing cycles on the internal structure of the NHSS-AC is the most drastic, and the freezing cycles will accelerate the development of microcracks. The soaking cycles is a process of deterioration of material. Especially in the spring-thaw season, various impurities and snow melt agent accelerates the mechanical performance loss of the asphalt binder. The scouring cycle removes the falling mortar particles and accelerates the development of water damage of pavement.

\section{Conclusions}

In this paper, NHSS modified asphalt concrete was prepared to systematically investigate the durability and the performance of NHSS modified asphalt concrete in spring-thawing season according to a self-designed laboratory freeze-soak-scour cycle test, and the freeze-soak-scour damage process of the NHSS modified asphalt concrete is studied by the logistic judgment model. Moreover, the influence of freezing, soaking, and scouring damage factors on the damage process of NHSS modified asphalt concrete in spring-thawing season is analyzed based on the gray rational degree theory. The main conclusions are as follows:

1. The durability and property test results of two mixtures after long-term freeze-soak-scour cycles illustrated that adding NHSS is an effective technique for mitigating freeze-thaw cycle damage of asphalt concrete in spring-thawing season.

2. The freeze-thaw-scour damage model of two mixtures were built and the damage speed and damage degree of the two mixtures were quantified based on the logistic judgment model. Model parameter $A_{\max }$ can be used to evaluate the damage degree of the mechanincal properties of asphalt cement, and the parameter $\mathrm{x}_{0.5}$ can be used to evaluate the damage speed of the properties of asphalt cement.

3. Through the application of the gray rational degree theory, it found that the freeze factor had a more significant impact on the damage process of NHSS-AC compared with the soak and scour factor. The impact of the scour factor on the durability of NHSS-AC was more significant than that of the soak factor, and the effect of the scour factor and soak factor on the low temperature mechanical performance was similar. 
Author Contributions: Conceptualization, X.G.; Data curation, W.G. and M.S.; Formal analysis, W.G., X.G., and W.D.; Funding acquisition, X.G.; Methodology, M.S., and W.D.; Project administration, W.D.; Writing-original draft, W.G.; Writing-review \& editing, X.G. and W.D.

Funding: This research was funded by the National Nature Science Foundation of China (NSFC) (grant no. 51178204). This financial support is gratefully acknowledged.

Conflicts of Interest: The authors declare that there is no conflict of interests regarding the publication of this paper.

\section{References}

1. Badeli, S.; Carte, A.; Dore, G.; Saliani, S. Evaluation of the durability and the performance of an asphalt mix involving Aramid Pulp Fiber (APF): Complex modulus before and after freeze-thaw cycles, fatigue, and TSRST tests. Constr. Build. Mater. 2018, 174, 60-71. [CrossRef]

2. El-Hakim, M.; Tighe, S.L. Impact of freeze-thaw cycles on mechanical properties of asphalt mixes. Transp. Res. Rec. 2014, 2444, 20-27. [CrossRef]

3. Shen, A.Q.; Lin, S.L.; Guo, Y.C.; He, T.Q.; Lyu, Z.H. Relationship between flexural strength and pore structure of pavement concrete under fatigue loads and Freeze-thaw interaction in seasonal frozen regions. Constr. Build. Mater. 2018, 174, 684-692. [CrossRef]

4. Biswas, S.; Hashemian, L.; Bayat, A. Investigation of pothole severity and maintenance methods in canada through questionnaire survey. J. Cold Reg. Eng. 2018, 32. [CrossRef]

5. Guo, S.C.; Dai, Q.L.; Hiller, J. Investigation on the freeze-thaw damage to the jointed plain concrete pavement under different climate conditions. Front. Struct. Civ. Eng. 2018, 32, 227-238. [CrossRef]

6. Badeli, S.; Carte, A.; Dore, G.; Saliani, S. Complex modulus and fatigue analysis of asphalt mix after daily rapid freeze-thaw cycles. J. Mater. Civ. Eng. 2018, 30. [CrossRef]

7. Yang, X.L.; Shen, A.Q.; Guo, Y.C.; Zhou, S.B.; He, T.Q. Deterioration mechanism of interface transition zone of concrete pavement under fatigue load and freeze-thaw coupling in cold climatic areas. Constr. Build. Mater. 2018, 160, 588-597. [CrossRef]

8. Gong, F.Y.; Ueda, T.; Wang, Y.; Zhang, D.W.; Wang, Z. Mesoscale simulation of fatigue behavior of concrete materials damaged by freeze-thaw cycles. Constr. Build. Mater. 2017, 144, 702-716. [CrossRef]

9. Ho, C.H.; Linares, C.P.M.; Shan, J.; Almonnieay, A. Material testing apparatus and procedures for evaluating freeze-thaw resistance of asphalt concrete mixtures. Adv. Civ. Eng. Mater. 2017, 6, 429-443. [CrossRef]

10. Xu, H.N.; Guo, W.; Tan, Y.Q. Internal structure evolution of asphalt mixtures during freeze-thaw cycles. Mater. Des. 2015, 86, 436-446. [CrossRef]

11. Si, W.; Li, N.; Ma, B. Impact of freeze-thaw cycles on compressive characteristics of asphalt mixture in cold regions. J. Wuhan Univ. Technol. Mater. Sci. Ed. 2015, 30, 703-709. [CrossRef]

12. Gong, X.; Romero, P.; Dong, Z.; Sudbury, D.S. The effect of freeze-thaw cycle on the low temperature properties of asphalt fine aggregate matrix utilizing bending beam rheometer. Cold Reg. Sci. Technol. 2016, 125, 101-107. [CrossRef]

13. Islam, M.R.; Asce, S.M.; Tarefder, R.A.; Asce, M. Effects of large freeze-thaw cycles on stiffness and tensile strength of asphalt concrete. J. Cold Reg. Eng. 2016, 30. [CrossRef]

14. Amini, B.; Tehrani, S.S. Simultaneous effects of salted water and water flow on asphalt concrete pavement deterioration under freeze-thaw cycles. Int. J. Pavement Eng. 2014, 15, 383-391. [CrossRef]

15. Wei, H.B.; Li, Z.Q.; Jiao, Y.B. Effects of diatomite and SBS on freeze-thaw resistance of crumb rubber modified asphalt mixture. Adv. Mater. Sci. Eng. 2017, 2017, 1-14. [CrossRef]

16. Klinsky, L.M.G.; Kaloush, K.E.; Faria, V.C.; Bardini, V.S.S. Performance characteristics of fiber modified hot mix asphalt. Constr. Build. Mater. 2018, 176, 747-752. [CrossRef]

17. Zhang, H.L.; Gao, Y.; Guo, G.H.; Zhao, B.J.; Yu, J.Y. Effects of ZnO particle size on properties of asphalt and asphalt mixture. Constr. Build. Mater. 2018, 159, 578-586. [CrossRef]

18. Qian, G.P.; Wang, K.; Bai, X.P.; Xiao, T.; Jin, D.Z.; Huang, Q.J. Effects of surface modified phosphate slag powder on performance of asphalt and asphalt mixture. Constr. Build. Mater. 2018, 158, 1081-1089. [CrossRef]

19. Hamedi, G.H. Evaluating the effect of asphalt binder modification using nanomaterials on the moisture damage of hot mix asphalt. Road Mater. Pavement Des. 2017, 18, 1375-1394. [CrossRef] 
20. Yao, H.; Dai, Q.L.; You, Z.P. Fourier Transform Infrared Spectroscopy characterization of aging-related properties of original and nano-modified asphalt binders. Constr. Build. Mater. 2015, 101, 1078-1087. [CrossRef]

21. Taherkhani, H.; Afroozi, S. Investigating the creep properties of asphaltic concrete containing nano-silica. Sādhanā 2018, 43, 24. [CrossRef]

22. Saltan, M.; Terzi, S.; Karahancer, S. Examination of hot mix asphalt and binder performance modified with nano silica. Constr. Build. Mater. 2017, 156, 976-984. [CrossRef]

23. Yao, H.; You, Z.P.; Li, L.; Lee, C.H.; Wingard, D.; Yap, Y.K.; Shi, X.M.; Goh, S.W. Rheological properties and chemical bonding of asphalt modified with nanosilica. J. Mater. Civ. Eng. 2013, 25, 1619-1630. [CrossRef]

2018 by the authors. Licensee MDPI, Basel, Switzerland. This article is an open access article distributed under the terms and conditions of the Creative Commons Attribution (CC BY) license (http://creativecommons.org/licenses/by/4.0/). 